First Peoples Child \& Family Review

A Journal on Innovation and Best Practices in Aboriginal Child Welfare Administration,

Research, Policy \& Practice

\title{
Editorial- The Insidious Poverty Epidemic: Considerations for Aboriginal Children, Families, Communities and other Indigenous Nations
}

\section{Marlyn Bennett and Cindy Blackstock}

Volume 3, Number 3, 2007

URI: https://id.erudit.org/iderudit/1069391ar

DOI: https://doi.org/10.7202/1069391ar

See table of contents

Publisher(s)

First Nations Child and Family Caring Society of Canada

ISSN

1708-489X (print)

2293-6610 (digital)

Explore this journal

Cite this document

Bennett, M. \& Blackstock, C. (2007). Editorial- The Insidious Poverty Epidemic: Considerations for Aboriginal Children, Families, Communities and other

Indigenous Nations. First Peoples Child \& Family Review, 3(3), 5-7.

https://doi.org/10.7202/1069391ar 


\title{
Editorial
}

\section{The Insidious Poverty Epidemic: Considerations for Aboriginal Children, Families, Communities and other Indigenous Nations}

\author{
Marlyn Bennett and Cindy Blackstock
}

\begin{abstract}
While the array of articles in this issue may appear to cover eclectic topics including: the implications of reconciliation for child welfare; the special needs of Aboriginal children; Aboriginal mothers' involvement with parenting programs; obesity issues among Aboriginal children; domestic trafficking of Aboriginal girls into the sex trade and the maltreatment of Aboriginal children and youth in Quebec, they are all tied together by one insidious common element - poverty. Poverty creates a fracture in the wealth of Canadian society - one where the have nots are often poorly regarded by those more fortunate and one where governments tend to only pay lip service to addressing the unequal distribution of a wealthy nation's resources. Aboriginal peoples are particularly disadvantaged with over one in every two Aboriginal children living below the poverty line and many Aboriginal communities struggling to get clean water to drink and healthy food to eat.
\end{abstract}

Each of the articles in this issue explore how poverty impacts the daily lives of children and youth involved with social service and child welfare agencies, not only in Canada but in other places such as Australia. Poverty among Indigenous peoples is a contemporary legacy of colonization that undermines the ability of Aboriginal families to nurture and support their children. Poverty is the new colonization - it overtakes the spirit, physical, emotional wellbeing and negatively affects cognitive potential. These articles all suggest - that unless we do something about poverty the gaps in life chances for Aboriginal children, youth and families will continue unabated.

This issue begins by centering the significance of establishing reconciliatory approaches for Aboriginal people affected by child welfare. Mr. Justice René Dussault's article regarding the path to reconciliation was based on a key note presentation he prepared for the Reconciliation in Child Welfare Conference held in November 2005 in Niagara Falls, which was jointly hosted by the First Nations Child \& Family Caring Society of Canada, the Centre of Excellence for Child Welfare, the National Indian Child Welfare Association, and the Child Welfare Leagues of Canada and America. In this opening article, Mr. Justice René Dussault, the former CoChair of Canada's Royal Commission on Aboriginal Peoples from 1991 to 1996, reflects on what he learned about how the broad range of colonial strategies, including residential schools, contributed to the pervasive poverty experienced by Aboriginal peoples. He also provides suggestions for how to proceed with reconciliation with Aboriginal peoples in the child welfare context.

Lack of service delivery for children with special needs is the focus of the next article about creating community responses to the needs of First Nations children in a remote northern First Nations community in Manitoba. Kinosao Sipi Minisowin Agency of Norway House, one of the largest First Nations in Manitoba, provides child and family services to status bearing Cree residents, living both on and off reserve within the province of Manitoba. Unfortunately disabled First Nations children do not enjoy a full and decent life, nor do they live in conditions that ensure their dignity, self-reliance and active participation in society. And more importantly the fact that disabled First Nations children do not enjoy a quality of life equal to that experienced by other Canadian children in similar circumstances, means that Canada has failed to live up to its responsibilities under the United Nations Convention on the Rights of the Child (CRC). Children and adolescents living in remote northern communities who have special 
needs face significant challenges as they often do not have equitable access to support and medical resources nor are their unique needs adequately considered in the broader persons with disabilities policy context. As a result, children with special needs are often referred to child welfare agencies to be admitted to foster care because of the absence of federally and provincially funded programs and services on reserves. This posed challenges for all involved, especially for the Kinosao Sipi Minisowin Agency in Norway, as it lacked the funding and resources to be able to respond to the complex medical needs presented by the special needs children referred to their agency. In other situations, First Nations families often face the heart breaking decision to leave their community so that their special needs children can access services outside the traditional family support systems available in their own communities. Although many non Aboriginal families of children with disabilities face challenges accessing the services their children need - Aboriginal children often experience problems even accessing the level of services that these non Aboriginal families find lacking as the federal and provincial governments argue over who should pay for services to status Indian children on reserve. To counteract the difficulty of making these kinds of decisions, the community created the "Kinao Sipi Children's Special Services Program" through community funds from the Norway House Cree Nation Community Master Implementation Agreement Trust Fund. This article by Ducharme, Muskego, Muswagon, Paupanekis, Muswagon, Spence and Ramdatt (hereafter "Ducharme, et al.") showcases the agency's innovative, but time limited approach, to how the needs of this special population are met within a frequently all too often environment characterized by service gaps, underfunding and jurisdictional conflicts over which level of government is fiscally responsible for services rendered to a special needs First Nations children placed into care by their families. Ducharme, et al. note that despite the success of the Children's Special Services Program it is still hampered by funding restrictions which prevent it from keeping pace with its own success. Decisions to cutback services have been made which means that future clients will be turned away and the range of services previously provided curtailed. Ducharme, et al., conclude by highlighting recommendations while also reiterating that First Nations families should not have to make unsuitable choices that detrimentally impact on the wellbeing of their children, their families and their communities.

Barbara Harris, Mary Russell and Annemarie Gockel (hereafter "Harris, et al.") look at the impact of poverty on a small sample of Aboriginal mothers who were involved in a longitudinal study regarding a Vancouver parenting program. Harris et al.'s interviews with Aboriginal mothers reveal that Aboriginal mothers are interested in prevention interventions (looking at colonial factors and the need for emotional support), paying attention to process (ensuring that interactions are collaborative, comfortable, continuous, client centered with clarity around expectations to help mothers reach their goals), addressing needs (i.e. transportation, flexibility, access to services on an on-going basis, need to learn new skills to reduce parenting difficulties and basic needs such as clothing, and access to a phone as ways of reducing the challenges of poverty), and delivered within a cultural context to ensure a healthy environment to raise their children. Relationship building between mothers and service providers as well as having meaningful strategies to deal with poverty are crucial factors in creating healthy environments. Access to cultural activities was identified as important to the wellness and healing of mothers to aid them in reducing stresses in working their way through the demands of the child welfare system. More importantly, the women stated that service providers must do more to understand the realities that come with poverty and that there are structural factors that Aboriginal mothers are powerless to change on their own. For instance, Aboriginal women have limited choices and difficulty obtaining adequate housing for their families predisposing them to contact with the child welfare system. Lastly, the authors of this article note that family preservation programs such as parenting programs are not sufficiently equipped to address the inequity experienced by these Aboriginal mothers and that further cutbacks to social programs reduce the ability of these programs to make meaningful impact on the lives of Aboriginal women and children living in poverty. Service providers would do well to include Aboriginal mothers in the design, delivery, the monitoring and evaluation of such programs as well as include Aboriginal women in the decision making process and policy development associated with parenting programs.

Cyndy Baskin shares the results of a research project exploring structural risk factors such as poverty and child welfare involvement on homelessness of urban Aboriginal youth in Toronto. Aboriginal youth are one of the fastest growing populations in Canada and thus homelessness for this population is increasing while non-Aboriginal populations are aging and thus will reduce over time. Housing for Aboriginal youth is needed to ensure their health and ability to participate as productive members of society. The purpose of Baskin's article was to examine the conditions under which Aboriginal youth became homeless as well as how homelessness among Aboriginal youth can be prevented and responded to. Baskin's article 
recommends policy changes and practical ways to ensure that Aboriginal peoples have some control over child welfare to ensure homelessness does not become an issue for future generations of Aboriginal youth. These suggestions come from the insightful and articulate perspectives of the youth who participated in Baskin's study as they know and understand many of the reasons behind their homelessness. Youth indicate that it is not enough that Aboriginal agencies are created and employ Aboriginal workers - the legislation, specifically, in child welfare, must be articulated from an Aboriginal perspective and must take into account the harm created by colonization and continuous poverty. This means creating Aboriginal specific policies including an Aboriginal Family and Child Services Act that would clearly differentiate between poverty and neglect as well as reflect Aboriginal values of collective responsibility for children, communal sharing of resources and assisting families when they are struggling rather than taking their children away. Equitable resources are required to ensure that poverty is eliminated so that families can adequately support their children and ensure their wellbeing into the future. Harris, et al. note that homelessness and poverty amongst the Aboriginal population are at unacceptable levels, especially given that this is the only homeland that Aboriginal peoples have ever known.

The social fallout resulting from colonization continues to rear its ugly head in the everyday lives of Indigenous people worldwide. Muriel Bamblett and Peter Lewis effectively paint a picture of the reality faced by Aboriginal populations in Australia as a result of colonization characterized by disempowerment, poverty, continuous disadvantages and cultural abuse. Using a rights based framework, the authors suggest how the non-Indigenous community and government can help Indigenous communities build a culturally respectful and competent service delivery system for Indigenous families so that communities of care can re-emerge and embrace Indigenous children, families, communities, culture and land.

Much of the research literature addressing human trafficking of young women into the sex trade fails to address the underlying reasons why Aboriginal girls are sexually exploited and/or may go missing in Canada. Anupriya Sethi indicates that Canada is rarely seen as country of origin from which girls, especially Aboriginal girls, are trafficked - rather Canada is seen more as a transit and destination country for other trafficked girls and women. Poverty is one of the main reasons why Aboriginal girls and women are forced into the sex trade at disproportionate rates. Unfortunately, people continue to wrongly believe that girls and women chose to be sexually exploited instead of appreciating that poverty often forces these women and girls into sex work in order to get their basic needs met (food and shelter). Sethi's article highlights important issues identified by the grassroots agencies working with sexually exploited Aboriginal girls and contextualizes their experiences within the trafficking framework in order to distinguish sexual exploitation from voluntary engagement in sex work.

Growing rates of obesity among Aboriginal youth is the topic of interest to Shelley Spurr. She advances a theoretical perspective suggesting that more parental and staff participation in school based policy decisions is a way to begin addressing this rising concern among Aboriginal youth. Poverty plays a significant role in the increasing rates of obesity for Aboriginal teens. Spurr believes that school is the best place in which parents and teachers can begin influencing healthy choices for overweight and obese Aboriginal youth and as a means for preventing obesity in future generations. Spurr reflects on the approach taken by one high school in Saskatchewan and in analyzing her approach to understanding the politics of policy development to end obesity of Aboriginal youth in the educational environment, she relied upon tools used by Deborah Stone from her book, Policy Paradox: The Art of Political Decision Making (2002). Above all else, Spurr believes that any successful anti-obesity strategy requires a collaborative approache from funders (i.e.: INAC) and provincial school boards.

The journal is proud to feature it's first French language article which is presented along side an English translation. This article speaks to the issue of maltreatment of Aboriginal children reported to youth protection services in Quebec. This article draws on the Quebec Incidence Study (1998) to compare reports of child maltreatment respecting Aboriginal and non-Aboriginal children in Quebec. The authors suggest that poverty is one of the key factors predisposing families to become involved with the child welfare system.

Collectively, these articles point out that poverty underlies many of the health and wellness disparities affecting Indigenous children, youth and families - if it goes unaddressed very little progress will be made in closing the gap in life chances and experience. Readers must never forget that there are real people connected to each of these articles. Their courageous struggle to overcome the ravages of poverty should compel us all to begin thinking more about the multiple aspects of poverty in the lives of Indigenous children, families, communities and nations and doing something concrete about it - because we can! 